\title{
Ocorrência fúngica em goiaba 'paluma' submetida a impacto e transportada em dois tipos de embalagens
}

\section{Fungal occurrence in guava 'paluma' submitted to impact and transported in two types of packaging}

\author{
Maciel dos Santos Freire ${ }^{1}$, Márcia Aparecida Cezar ${ }^{2}$, Railene Hérica Carlos Rocha Araújo ${ }^{3}$, Francisco de Assis de Souza ${ }^{4}$, \\ Tiago Augusto Cardoso de Lima ${ }^{5}$
}

\begin{abstract}
Resumo: No Nordeste, é comum a utilização de embalagens inadequadas para transporte de frutos,acarretando injúrias que servem como porta de entrada de patógenos. Objetivou-se avaliar a incidência de podridão, severidade e ocorrência fúngica em goiaba 'Paluma' transportada em dois tipos de embalagens. Frutos foram colhidos na Fazenda Mocó, Aparecida, Paraíba, no estádio de maturação "de vez", e submetidos aos tratamentos por impacto através de queda à altura de $85 \mathrm{~cm}$ sob piso industrial, caracterizando os tratamentos: $\mathrm{T}_{1}$, frutos submetidos a impacto, embalagem em caixa plástica de polietileno; $\mathrm{T}_{2}$, frutos submetidos a impacto, embalagem em caixa de papelão; $\mathrm{T}_{3}$, frutos sem impacto, embalagem em caixa plástica de polietileno; $\mathrm{T}_{4}$, frutos sem impacto, embalagem em caixa de papelão; $\mathrm{T}_{5}$, testemunha, frutos sem injúria mecânica. As amostras foram transportados por $45 \mathrm{~km}$, até o Laboratório de Fitopatologia da Universidade Federal de Campina Grande, Campus Pombal. Os resultados de severidade mostraram que o tratamento $\mathrm{T}_{1}$ difere significativamente dos demais. Os tratamentos $\mathrm{T}_{1} \mathrm{e}$ $\mathrm{T}_{2}$ apresentaram maior incidência de frutos com podridões. A maior ocorrência de fungos foi verificada nos tratamentos com caixa plástica, mostrando que este tipo de embalagem favorece a incidência fúngica.
\end{abstract}

Palavras-chave: Psidium guajava L.; Fitopatógenos; Severidade

\begin{abstract}
In the Northeast it is common the use of inadequate packaging for fruit transportation, causing injuries that serve as pathogen gateway. This study aimed to evaluate the incidence of rot, fungal severity and occurrence in guava 'Paluma' transported in two types of packaging. Fruits were collected at farm Mocó, Aparecida - PB during maturation "of time," and subjected to treatment by impact through the fall height of $85 \mathrm{~cm}$ under industrial floor, featuring treatments: T1, fruits subjected to impact, packaging in plastic polyethylene box; T2, fruits subjected to impact, packing in cardboard box; T3, fruit without impact, packaging in plastic polyethylene box; T4, fruit without impact, packing in cardboard box; T5, witness, fruit without mechanical injury. These were carried by $45 \mathrm{~km}$, to the Phytopathology Laboratory of CCTA. The results show that the severity of the treatment $\mathrm{T} 1$ differs significantly from the others. The T1 and T2 had a higher incidence of decayed fruits.
\end{abstract}

Keywords: Psidium guajava L.; Plant pathogens; Severity

\footnotetext{
*Autor para correspondência

Recebido para publicação em 24/07/2016; aprovado em 10/06/2017

${ }^{1}$ Eng. Agro. Mestre em Agronomia/Fitotecnia, CCA/UFC, Fortaleza-CE, maciellfreire@ hotmail.com, Tel. 84996501362

${ }^{2}$ Eng(a). Agro. Dra. Sc., Professora titular da Universidade Federal da Paraíba, DTS/UFPB, marciaapcezar@gmail.com, Tel. 83996270030

${ }^{3}$ Eng(a). Agro. Dra. Sc., Professora titular da Universidade Federal de Campina Grande, CCTA/UFCG, raileneherica@ccta.ufcg.edu.br, Tel. 83 996630227

${ }^{4}$ Eng. Agro. CCTA/UFCG, franciscoufcg@gmail.com, Tel. 83998204819

${ }^{5}$ Biólogo Dr. Universidade Federal de Campina Grande, CCTA/UFCG, tiagoipj@ yahoo.com.br, Tel. 83987802066
} 


\section{INTRODUÇÃO}

A goiaba ocupa lugar expressivo no contexto da fruticultura brasileira, com produção anual de aproximadamente 359,4 toneladas, segundo Instituto Brasileiro de Geografia e Estatística (IBGE, 2014). Grande parte destas goiabas é produzida por agricultores familiares que estão expandindo sua produção, isso se deve não só ao crescente consumo de fruta fresca, mas também aos produtos de sua industrialização, como sucos, geleias, frutas cristalizadas e doces (OLIVEIRA et al., 2012).

No Brasil, a goiabeira é cultivada desde o Rio Grande do Sul até o Maranhão, destacando-se os estados de São Paulo, Pernambuco, Minas Gerais e Bahia como os maiores produtores, responsáveis por aproximadamente $73,7 \%$ da produção nacional da fruta,sendo considerado o Nordeste como o maior produtor, responsável por $42,77 \%$ da produção de goiabas no país (IBGE, 2014).

A Paraíba é o quinto estado produtor de goiaba, sendo a maior produção concentrada na região do sertão paraibano entre os municípios de Condado, Patos, Sousa, Cajazeiras, Cachoeira dos Índios, São João do Rio do Peixe, Uiraúna, Santa Helena e Triunfo (LOPES et al., 2010).Nessas localidades têm-se utilizado caixas de madeira ou plástico, e até mesmo os frutos soltos sem embalagens, depositados na carroceria dos transportes. Esses tipos de embalagens e transporte dos frutos contribuem para a sua depreciação uma vez que são comumente trazidos diretamente do campo para o comércio em supermercados e feiras livres sem o devido cuidado e proteção, o que confere uma aparência ruim e qualidade inferior ao produto.

$O$ tipo de material utilizado na embalagem deve ser escolhido criteriosamente visando a sanidade e qualidade dos frutos. As caixas de madeira apresentam características relacionadas à aspereza da madeira, que prejudicam o alimento e dificulta, a higienização da própria caixa que, em contato com a água, se torna úmida e favorece o surgimento e crescimento de fungos. Além disso, a reutilização da caixa de madeira, passando por diferentes elos da cadeia hortifrutícola, torna-se um agente disseminador de doenças, principalmente na pós-colheita (LORENZI et al., 2014).

Em frutos de goiaba é comum à ocorrência de danos por impacto, compressão, corte e abrasão. Ao decorrer da cadeia de comercialização estes danos têm efeito cumulativo, verificando-se maior incidência no transporte $\mathrm{e}$ comercialização (PASINI, 2012).

Diversos trabalhos avaliando a qualidade pós-colheita foram realizados e constataram que frutos comercializados em centrais de abastecimento, feiras livres e supermercados têm a qualidade afetada por danos mecânicos, heterogeneidade de estádio de maturação, formato e tamanho (FARIAS et al., 2007; XAVIER et al., 2009).

Estes danos podem alterar o metabolismo, prejudicar os atributos físicos, químicos e a aparência dos frutos, podendo também facilitar a entrada de patógenos que aceleram os processos de deterioração, desvalorizando os produtos para comercialização (CHITARRA;CHITARRA, 2005). A quantificação e caracterização dos danos são importantes, pois apontam à cadeia de comercialização a necessidade de investimento em medidas de prevenção (LEITE et al., 2010). Os danos causados em frutos de goiaba podem ser originários do tipo de embalagem utilizada, estas causam grandes prejuízos.

Problemas de origem fitossanitária em goiabas são provenientes do uso das embalagens inadequadas que são utilizadas tanto para transporte como para armazenamento. $\mathrm{O}$ tipo de embalagem pode proporcionar injúrias que prejudicam diretamente a qualidade dos frutos, atuam como porta de entrada de patógenos, contribuem na ocorrência de podridões que depreciam o produto. A utilização de embalagens adequadas para o transporte e acondicionamento dos frutos seria uma alternativa para minimizar as perdas.

Dessa forma, objetou-seavaliara influência do impacto e o tipo de embalagens de transporte na ocorrência fúngica em goiaba 'paluma'.

\section{MATERIAL E MÉTODOS}

A pesquisa foi desenvolvida no período de novembro de 2012 a fevereiro de 2013, no laboratório de Fitopatologia do Centro de Ciências e Tecnologia Agroalimentar (CCTA) da Universidade Federal de Campina Grande (UFCG). As goiabas 'Paluma' foram colhidas cuidadosamente pela manhã, em um pomar agrícola localizado na Fazenda Mocó, município de Aparecida - PB. Foram colhidos frutos no estádio de maturação "de vez" correspondente à coloração verde-mate (Pereira, 1995). Após a coleta, os frutos foram levados para um galpão na própria fazenda para a aplicação dos tratamentos.

Utilizou-se o delineamento experimental de blocos inteiramente casualizados com cinco tratamentos com quatro repetições e dois frutos por unidade experimental.

Os tratamentos foram estabelecidos, simulando-se impactos que possam, por ventura, ocorrer na casa de embalagem. Procedeu-se da seguinte forma: $T_{1}$, frutos submetidos a impacto, embalagem em caixa plástica de polietileno; $\mathrm{T}_{2}$, frutos submetidos a impacto, embalagem em caixa de papelão; $\mathrm{T}_{3}$, frutos sem impacto, embalagem em caixa plástica de polietileno; $\mathrm{T}_{4}$, frutos sem impacto, embalagem em caixa de papelão; $T_{5}$, testemunha, frutos sem injúria mecânica. Após a aplicação dos tratamentos, os frutos foram acondicionados em uma única camada s dois impactos em cada fruto, em lados opostos, na região equatorial. Para identificar o local em que o fruto sofreu o impacto, foi posta sob o piso uma etiqueta adesiva que se fixava nos frutos no momento do contato com o piso. Utilizou-se caixas de papelão do tipo telescópica (tampa e fundo) com dimensões externas de 7x20x31cm; e a de plástico do tipo polietileno com dimensões externas de 556 x 360 x $311 \mathrm{~mm}$. Os frutos foram transportados para a Universidade Federal de Campina Grande (UFCG) por um percurso de $30 \mathrm{~km}$ em estrada asfaltada e $15 \mathrm{~km}$ de estrada vicinal, no compartimento de carga (no piso da parte traseira) do veículo, simulando as condições do trajeto percorrido até chegar ao comércio de Pombal - PB.

Para a análise da incidência e severidade de podridões e patógenos fúngicos em frutos de goiaba provenientes do campo, estes foram levados ao laboratório de Fitopatologia, do CCTA/UFCG e posteriormente lavados com água e detergente neutro e colocados para secar durante $30 \mathrm{~min}$ em temperatura ambiente.

Após a lavagem, os frutos foram submetidos à desinfestação superficial por meio da aspersão de álcool 70\%, 
procedendo-se a incubação individual dos mesmos em câmara úmida, ou seja, envolto por um plástico contendo um chumaço de algodão hidrófilo umedecido com água destilada e esterilizada (ADE), dispostos sobre bancadas em temperatura ambiente por $48 \mathrm{~h}$, e posteriormente foram avaliados quanto à incidência de podridões, considerando a porcentagem de frutos com sintomas visíveis da doença em relação ao total de frutos.

Após o período de incubação em câmara úmida,a severidade de doença e/ou sinais de patógenos em cada fruto foi avaliada pela média resultante das observações visuais realizadas por três avaliadores, sendo a ocorrência de podridões, determinada pela escala de notas que variam de 0 a 4, onde: a) 0, Frutos sem sintomas de manchas e podridão e sem estruturas fúngicas; b) 1, Frutos com sintomas iniciais (10\%) de podridão e sem estruturas fúngicas; c) 2, Frutos com sintomas de podridão (20\%) e com estruturas fúngicas; d) 3, Frutos com sintomas de podridão (30\%) com estruturas fúngicas; e) 4, Frutos com sintomas de podridão (50\%) com diferentes estruturas fúngicas.

Os valores da média do número de lesões por fruto/tratamento foram obtidos através da contagem e soma do número de lesões presentes em todos os frutos (8) de um determinado tratamento após câmara úmida, consequentemente o resultado foi dividido pelo número total de frutos do tratamento proporcionando o resultado final, obtendo-se assim o valor médio por tratamento.

Para a confirmação da identidade e frequência de patógenos fúngicos nos frutos, estes foram submetidos ao isolamento (ALFENAS;MAFIA, 2007), que consistiu na retirada de fragmentos superficiais das margens das lesões, seguida da desinfestação superficial (álcool $70 \%$ por 30 segundos, hipoclorito de sódio $2 \%$ por um minuto e duas lavagens em água destilada esterilizada).A seguir, foram plaqueados em meio de cultura BDA (Batata-dextrose-agar), acrescido de cloranfenicol $\left(0,05 \mathrm{~g} \mathrm{~L}^{-1}\right)$. As placas foram mantidas em estufa incubadora tipo B.O.D a $28 \pm 2{ }^{\circ} \mathrm{C}$ por sete dias, com fotoperíodo de $12 \mathrm{~h}$. Após esse período, foram identificados os patógenos que ocorreram nos frutos sintomáticos com o auxílio de um microscópio óptico observando-se características morfológicas, tais como identificação dos esporos, e culturais, como pigmentação e estrutura do micélio.

Os dados foram submetidos à análise de variância e teste de comparação de médias (Tukey) a 5\% de probabilidade utilizando-se o programa SISVAR (FERREIRA, 2008).

\section{RESULTADOS E DISCUSSÃO}

Menores incidências de frutos com podridão foram verificadas nos tratamentos sem adição de impacto $\left(\mathrm{T}_{3} \mathrm{e} \mathrm{T}_{4}\right)$, destacando-se a embalagem de papelão que proporcionou a menor incidência em relação à embalagem plástica. Entretanto, nos tratamentos onde foram submetidos os impactos houve $100 \%$ de frutos com podridão (Figura 01). Não foram verificados frutos com podridões no tratamento que constituiu a testemunha (T5), isso devido aos cuidados no manuseio e transporte dos mesmos.
Figura 1. Incidência de podridão em frutos de goiaba da cultivar 'Paluma'submetida ou não a impacto e transportada em dois tipos de embalagens. $\mathrm{T}_{1}$, frutos submetidos a impacto, embalagem em caixa plástica de polietileno; $\mathrm{T}_{2}$, frutos submetidos a impacto, embalagem em caixa de papelão; $T_{3}$, frutos sem impacto, embalagem em caixa plástica de polietileno; $\mathrm{T}_{4}$, frutos sem impacto, embalagem em caixa de papelão; $\mathrm{T}_{5}$, testemunha, frutos sem injúria mecânica. Pombal, Paraíba

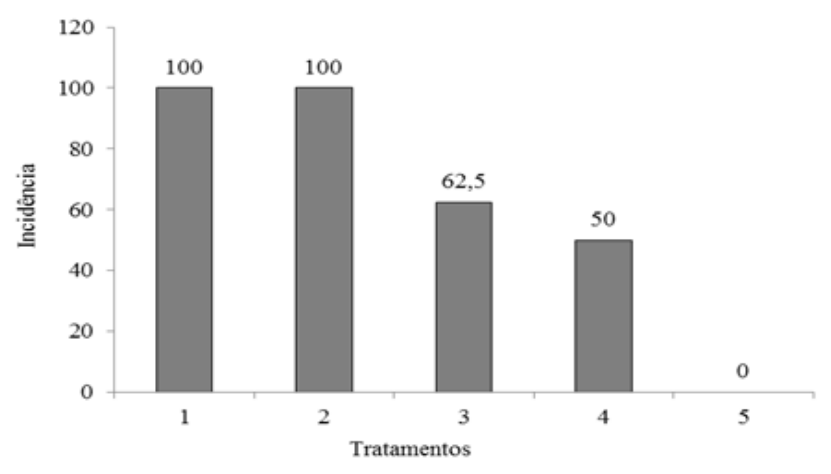

Após a análise fitopatológica, verificou-se que os tratamentos envolvendo impacto nos frutos $\left(\mathrm{T}_{1}\right.$ e $\left.\mathrm{T}_{2}\right)$ obtiveram maiores notas de severidade de doenças, diferindo estatisticamente entre si, demonstrando que o tratamento que utilizou a caixa de papelão $\left(\mathrm{T}_{2}\right)$ apresentou menores valores em relação aos frutos transportados em caixa plástica $\left(\mathrm{T}_{1}\right)$ (Tabela 01). Isso pode ser atribuído, provavelmente, não apenas ao impacto aos quais os frutos foram submetidos, mas também principalmente ao tipo de embalagem utilizado que causou a predisposição dos frutos aos ferimentos durante o transporte. Nos demais tratamentos $\left(\mathrm{T}_{3}, \mathrm{~T}_{4}\right.$ e $\left.\mathrm{T}_{5}\right)$, nos quais não houve adição de impacto, o número de lesões foi inferior e não houve presença de estruturas fúngicas.

Tabela 1. Valores médios de severidade da doença e número médio de lesões em frutos de goiaba submetidos ou não a impacto e transportada em dois tipos de embalagens Pombal, Paraíba

\begin{tabular}{ccc}
\hline Tratamento & $\begin{array}{c}\text { Severidade } \\
\text { da Doença }\end{array}$ & $\begin{array}{c}\text { Número médio } \\
\text { de lesões }\end{array}$ \\
\hline T1 & $1,37 \mathrm{a}$ & $7,75 \mathrm{a}$ \\
T2 & $1,00 \mathrm{~b}$ & $3,25 \mathrm{~b}$ \\
T3 & $0,00 \mathrm{c}$ & $1,70 \mathrm{~b}$ \\
T4 & $0,00 \mathrm{c}$ & $1,75 \mathrm{~b}$ \\
T5 & $0,00 \mathrm{c}$ & $0,00 \mathrm{~b}$ \\
\hline CV & $23,54 \%$ & $64,94 \%$ \\
\hline
\end{tabular}

Médias seguidas da mesma letra na coluna, não diferem entre si pelo teste de Tukey ao nível de $5 \%$ probabilidade. $\mathrm{T}_{1}$, frutos submetidos a impacto, embalagem em caixa plástica de polietileno; $\mathrm{T}_{2}$, frutos submetidos a impacto, embalagem em caixa de papelão; $T_{3}$, frutos sem impacto, embalagem em caixa plástica de polietileno; $\mathrm{T}_{4}$, frutos sem impacto, embalagem em caixa de papelão; $T_{5}$, testemunha, frutos sem injúria mecânica.

A avaliação da qualidade da goiaba quando transportadas em diferentes embalagens constatou que os frutos após cinco dias de armazenamento, em temperatura ambiente, tinham estruturas fúngicas e $20 \%$ da casca afetada por sintomas de podridão (SILVA et al.,2015). Durigan et al. (2005) observaram presença de podridões em lima ácida 'Tahiti' com injúrias por impacto. Steffensi et al. (2008) constataram que maçãs submetidas a impacto tiveram maior incidência de 
podridões $(28,1 \%)$, quando comparadas com os frutos sem danos $(3,3 \%)$, nove dias após a injúria.

Esses dados evidenciam que os ferimentos, injúrias mecânicas provocadas em grande parte pelo manuseio e transporte inadequados são fundamentais para a infecção de patógenos que causam doenças típicas em pós-colheita, tais ferimentos podem favorecer a penetração dos patógenos quiescentes nos frutos. Além disso, verifica-se que o valor do número médio de lesões nos frutos submetidos a impacto, e transportados em caixas plásticas de polietileno $\left(T_{1}\right)$, foi estatisticamente superior aos demais, constatando-se assim que trata-se de uma embalagem inadequada para o transporte de frutos de goiaba.

Após o isolamento, verificou-se (Figura 02), sendo os de maior ocorrência Aspergillus flavus, Aspergillus nigere Penicillium sp.

Figura 2. Ocorrência e frequência fúngica em frutos de goiaba 'Paluma' submetida ou não a impacto e transportada em dois tipos de embalagens. $\mathrm{T}_{1}$, frutos submetidos a impacto, embalagem em caixa plástica de polietileno; $\mathrm{T}_{2}$, frutos submetidos a impacto, embalagem em caixa de papelão; $\mathrm{T}_{3}$, frutos sem impacto, embalagem em caixa plástica de polietileno; $\mathrm{T}_{4}$, frutos sem impacto, embalagem em caixa de papelão; $\mathrm{T}_{5}$, testemunha, frutos sem injúria mecânica.

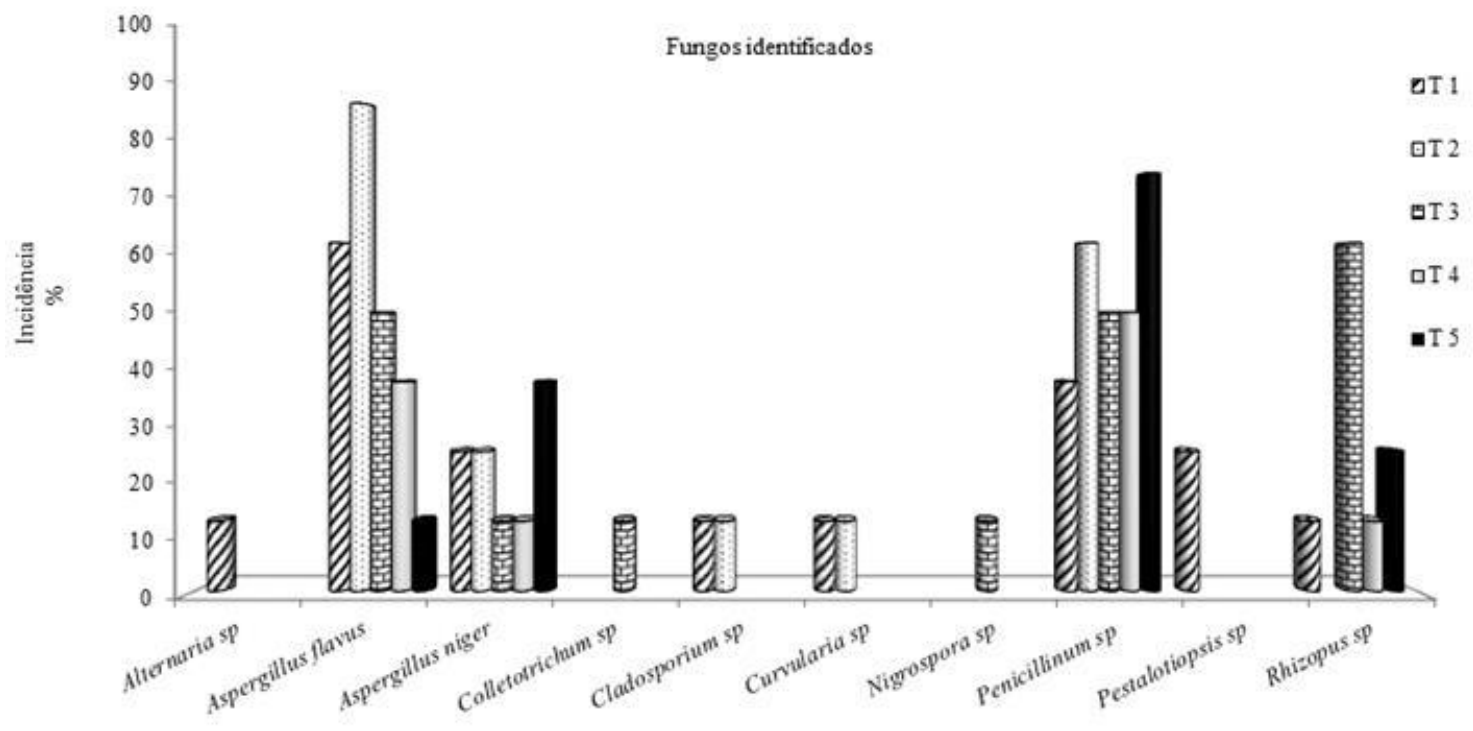

Os tratamentos que utilizaram caixas plásticas de polietileno $\left(T_{1}\right.$ e $\left.T_{3}\right)$ tiveram as maiores incidências fúngicas, sobretudo quando houve o impacto $\left(\mathrm{T}_{1}\right)$ (Figura 02). Provavelmente, a embalagem plástica não impediu o deslocamento eatrito entre os frutos durante o transporte dos mesmos, facilitando assim a entrada de patógenos. Neste tratamento foram identificados oito gêneros fúngicos, sendo ode maior frequência Aspergillus flavus (62,5\%). Além deste, verificou-se a presença de Penicillium sp, Aspergillus niger, Cladosporium sp, Pestalotiopsis sp, Alternaria sp, Curvularia sp, e Rhizopus sp (Figura 02).

Apesar do impacto, houve redução da incidência fúngicano tratamento comtransporte dos frutos em caixas de papelão $\left(\mathrm{T}_{2}\right)$, em relação ao tratamento impacto e transporte em caixa plástica $\left(\mathrm{T}_{1}\right)$ (Figura02). Neste tratamento identificou-se os gêneros Penicillium sp, Aspergillus niger, Cladosporium sp, Curvularia sp e Aspergillus flavus sendo este último com incidência de $87,5 \%$.

As elevadas incidências de Aspergillus spp. observadas no presente trabalho são preocupantes devido à sua capacidade de produzir micotoxinas. Tais micotoxina de acordo com Maziero e Bersot (2010), representam grave risco à saúde humana devido aos seus efeitos tóxicos imediatos.

Cavalcanti et al. (2005), estudando a podridão póscolheita causada por Aspergillus niger em uvas constataram que essa é uma doença ocorrente em todas as fases de desenvolvimento das uvas, podendo, portanto, ser uma infecção adquirida ou não. Constatou-se que os cachos coletados diretamente do campo, apesar de não apresentar sintomas, já apresentavam presença quiescente do patógeno.
Em um estudo sobre danos pós-colheita em goiabas no mercado, realizado por Martins et al. (2007), foi verificado que a doença de maior incidência foi pinta-preta (Guignardia psidii), observada em 3,5\% dos frutos. Sintomas de antracnose foram observados em 1,1\% dos frutos. Menos de $1 \%$ dos frutos apresentaram podridões de Fusicoccum, Pestalotia, Rhizopus e Cladosporium.

De acordo com Xavier et al. (2009) avaliando a qualidade pós-colheita de manga 'Tommy Atkins' comercializada em diferentes estabelecimentos comerciais no município de Mossoró-RN verificaram as presenças dos patógenos $C$. gloeosporioides, A. alternata, Aspergillus spp., $L$. theobromae e Rhizopus spp. em manga.

Pereira et al. (2010) constataram em frutos de banana 'Prata', 'Maçã' e 'Nanica' comercializados na feira livre de Pombal - PB a presença dos fungos Colletotrichum sp, Curvularia sp, Fusarium sp., Phomopsis sp e Trichoderma sp.,Aspergillus sp, Penicillium sp e Rhyzopus sp, sendo os fungos do gênero Colletotrichum sp e Rhizopus sp os que ocorreram com maior frequência.

No tratamento que utilizou caixas plásticas no transporte de frutos sem adição de impacto $\left(\mathrm{T}_{3}\right)$, verificou-se a incidência dos gêneros fúngicos Rhizopus detectado em 62,5\% dos frutos analisados, seguido de Penicillium sp, Aspergillu sflavus, A. niger, Colletotricum sp e Nigrospora $\mathrm{sp}$ (Figura03).

De acordo com Chitarra e Chitarra(2005), o ataque por microrganismos é provavelmente uma das causas mais sérias de perdas pós-colheita nos produtos perecíveis. Inicialmente ocorre uma infecção por um ou mais patógenos, podendo ou 
não ocorrer infecções secundárias. Embora esses patógenos secundários sejam fracamente patogênicos, podem sobreviver no tecido doente ou morto, aumentando os danos nos tecidos.

Segundo Choudhury et al. (2001), as deteriorações patológicas pós-colheita da goiaba estão associadas aos seguintes fitopatógenos: Colletotrichum gloeosporioides, Lasiodiplodia theobromae, Phomopsis destructum, P. psidii, Curvalaria tuberculata, Aspergillus niger, A. flavus, Rhizophus stolonifer, R.oryzae, Pestalotiopsis psidii, Penicillium spp. e Alternaria spp.

Segundo Silveira et al. (2005) tentativas de controle de doenças pós colheita em frutas, baseadas em poucas informações sobre os patógenos, podem levar a baixa ou nenhuma redução do problema, bem como elevarem os custos sem um aumento substancial na qualidade dos produtos.

$\mathrm{O}$ tratamento em que os frutos não sofreram impactos e foram transportados em caixas de papelão (T4) apresentou o menor índice de patógenos, sendo observado: Penicillium $s p$, Aspergillus flavus, Aspergillus niger, e Rhizopus sp nas proporções de 50; 37,5; 12,5 e 12,5\% respectivamente (Figura 02). Entretanto, a incidência dos fungos Lasiodiplodia theobromae, Colletotrichum gloeosporioides, Fusarium spp., Alternaria alternata, Rhizopus spp., Aspergillus spp., Curvularia spp. e Penicillium spp., na pós-colheita, foi verificada em mamões embalados em caixas de diferentes materiais e formatos, transportados de diferentes formas, até os estabelecimentos comerciais (ROCHA et al., 2015).

Além de tratamentos fitossanitários adequados na pré e pós-colheita, o manejo das podridões em frutos deve incluir cuidados na manipulação no momento da colheita, evitandose impactos e ferimentos,bem como deve utilizar-se de embalagens adequadas no transporte do campo até o local de comercialização.

\section{CONCLUSÕES}

Os impactos nos frutos associados ao transporte em caixa plástica propiciaram maior severidade de doença e maior número médio de lesões; o caixas plásticas e de papelão submetidos ao impacto apresentaram maior incidência de podridão;

As caixas plásticas proporcionaram maior ocorrência fúngica, independente do impacto;

Os fungos que ocorreram com maior frequência foram, Aspergillusflavus, Penicillinumsp, seguido de Rhizopuse A. niger.

\section{REFERÊNCIAS}

ALFENAS, A. C.; MAFIA, R. G. Métodos em fitopatologia. Viçosa:Editora UFV, 2007. 382p.

CAVALCANTI, L. S.; DI PIERO, R. M.; CIA, P.; PASCHOLATI, S. F.; RESENDE, M. L. V.; ROMEIRO, R.S. Indução de resistência em plantas a patógenos e insetos.Piracicaba:FEALQ, 2005. 263P.

CHITARRA, M. I. F.; CHITARRA, A .B. Pós-colheita de frutos e hortaliças: fisiologia e manuseio. $2^{\mathrm{a}}$ ed. Lavras: UFLA, 2005. 785p.

CHOUDHURY, M. M.; ARAÚJO, J. L. P.; GONZAGA NETO, L.; RESENDE, J. M.; COSTA, T. S. da;
SCCAGGIANTE, G. Goiaba: Pós-colheita. Brasília: EMBRAPA - Informações Técnológicas (Frutas do Brasil), 2001. 45p.

DURIGAN, M. F. B.; MATTIUZ, B-H.; DURIGAN, J. F. Injúrias mecânicas na qualidade pós-colheita de lima ácida 'Tahiti' armazenada sob condição ambiente. Revista Brasileira deFruticultura,v.27, n.3, p.369-372, 2005.

FARIAS, J. F.; SILVA, L. J. B.; NETO, S. E. A.; Mendonça, V.Qualidade do maracujá-amarelo comercializado em Rio Branco, Acre. Revista Caatinga. v.20, n.3, p.196-202, 2007.

FERREIRA, D. F. Sisvar: Um programa para análises e ensino de estatística. Revista Symposium.v.6, p.36-41, 2008.

IBGE. Instituto brasileiro de geografia e estatística, Anuário estatístico do Brasil;Vol. 74, 2014. <http://www.sidra.ibge.gov.br>. 25 mar. 2016.

LEITE, G. A.; MEDEIROS, E. V.; MENDONÇA, V.; MORAES, P. L. D.; LIMA, L. M.; XAVIER, I. F. Qualidade pós-colheita da banana 'Pacovan' comercializada em diferentes estabelecimentos no município de Mossoró-RN. Revista Brasileira de Ciências Agrárias.v.5, n.3, p.322-327, 2010 .

LOPES, E. B.; BRITO, C. H.; BATISTA, J. L.; SILVA, A. B. Ocorrência do nematoide Meloidogyne mayaguensis em goiabeira (Psidiumguajava) no estado da Paraíba. Revista Tecnologia e Ciência Agropecuária.v.4, n.2, p.12-16, 2010.

LORENZI, C. O.; JULIÃO, L.; SANTOS, F. G. R.; OLIVEIRA, F. V. Embalagens das "de sempre" para as sofisticadas. Hortifruti Brasil. v.12, n.137, p.08-23, 2014.

MAZIERO, M. T.; BERSOT, L. S. Micotoxinas em alimentos produzidos no Brasil. Revista Brasileira de Produtos Agroindustriais. v.12, n.1, p.89-99, 2010.

MARTINS, M. C.; AMORIM, L.; LOURENÇO, S. A.; GUTIERREZ, A. S. S.; WATANABE, H. S. Incidência de danos pós-colheita em goiabas no mercado atacadista de São Paulo e sua relação com a prática de ensacamento dos frutos.Revista Brasileira de Fruticultura, v.29, p.245-248, 2007.

OLIVEIRA, I. P.; OLIVEIRA, L. C.; MOURA, C. S. F. T.; JÚNIOR, A. F. L.; ROSA, S. R. A. Cultivo da goiabeira: do manejo da planta ao armazenamento de frutos. Revista Faculdade Montes Belos. v.5, n.4, 2012.

PASINI, J. Avaliação de danos mecânicos nas etapas de transporte, beneficiamento e comercialização de peras. Porto Alegre:Universidade Federal do Rio Grande do Sul, 2012. 112 f. Dissertação de mestrado.

PEREIRA, V. M. O.; AMBRÓSIO, M. M. Q.; QUEIROGA, R. Q. F.; SOUSA, J. S.; WANDERLEY, J. A. C. Incidência e frequência de fungos em bananas comercializadas na feira livre de Pombal - PB. Revista Verde.v.5, n.4, p.55-60, 2010. 
PEREIRA, F. M. Cultura da goiabeira. 1. ed. Jaboticabal: FUNEP, 1995. 47p.

ROCHA, R. H. C.; CEZAR, M. A.; SATIRO, D. D. S.; SILVA, H. S.; SOUSA, F. A.Características físico-químicas e incidência de patógenos fúngicosem mamão formosa comercializado no sertão paraibano. Revista Brasileira de Produtos Agroindustriais. v.17, n.3, p.199-205, 2015.

SILVA, H. S.; MOREIRA, I. S.; FURTUNATO, T. C.; HÉRICA, R. H.; SOUSA, F. A. Caixas para o transporte interno e armazenamento da goiaba 'Paluma' com injúria de impacto. Revista Verde de Agroecologia e Desenvolvimento Sustentável.v.10, n.1, p.128-136, 2015.

SILVEIRA, N. S. S.; MICHEREFF, S. J. M.; SILVA, I. L. S. S.; OLIVEIRA, S. M. A. Doenças fúngicaspós-colheita em frutas tropicais: patogênese e controle. Revista Caatinga.v.18, n.4, p. 283-299, 2005.

STEFFENSI, C. A.; ESPÍNDOLA, B. P.; AMARANTE, C. V. T.; SILVAIRA, J. P. G.; CHECHI, R.; BRACKMANN, A. Respiração, produção de etileno e qualidade de maçãs "Gala" em função do dano mecânico por impacto e da aplicação de 1-metilciclopropeno. Ciência Rural. v.38, n.7, p.1864-1870, 2008.

XAVIER, I. F.; LEITE, G. A.; MEDEIROS, E. V.; MORAES, P. L. D.; LIMA, L. M. Qualidade pós-colheita de manga 'Tommy Atkins' comercializada em diferentes estabelecimentos comerciais no município de Mossoró-RN. Revista Caatinga v.22, n.4, p.7-13, 2009. 